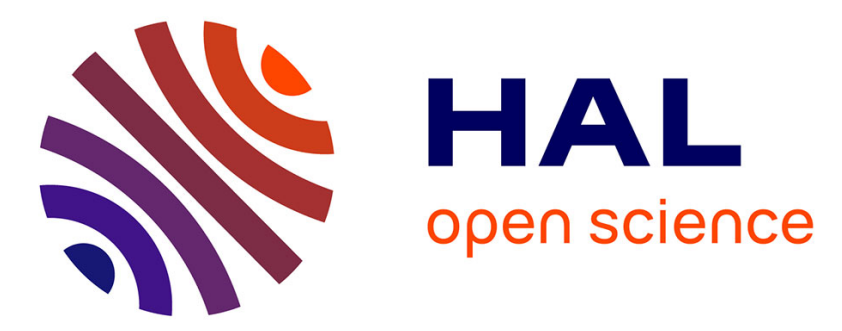

\title{
Barriers and Success Factors for Continuous Improvement Efforts in Complex ETO Firms
}

Emrah Arica, Kristoffer Magerøy, Marta Lall

\section{To cite this version:}

Emrah Arica, Kristoffer Magerøy, Marta Lall. Barriers and Success Factors for Continuous Improvement Efforts in Complex ETO Firms. IFIP International Conference on Advances in Production Management Systems (APMS), Aug 2018, Seoul, South Korea. pp.124-130, 10.1007/978-3-319-997049_16. hal-02164902

\section{HAL Id: hal-02164902 \\ https://hal.inria.fr/hal-02164902}

Submitted on 25 Jun 2019

HAL is a multi-disciplinary open access archive for the deposit and dissemination of scientific research documents, whether they are published or not. The documents may come from teaching and research institutions in France or abroad, or from public or private research centers.
L'archive ouverte pluridisciplinaire HAL, est destinée au dépôt et à la diffusion de documents scientifiques de niveau recherche, publiés ou non, émanant des établissements d'enseignement et de recherche français ou étrangers, des laboratoires publics ou privés. 


\title{
Barriers and Success Factors for Continuous Improvement Efforts in Complex ETO Firms
}

\author{
Emrah Arica $^{1}$, Kristoffer Magerøy ${ }^{1}$, and Marta Therese Mathisen Lall ${ }^{1}$ \\ ${ }^{1}$ SINTEF Technology and Society, Department of Economics and Technology Management, \\ Trondheim, Norway \\ emrah.arica@sintef.no
}

\begin{abstract}
This paper focuses on the factors that may influence the implementation of continuous improvement efforts, in an Engineer-to-Order (ETO) manufacturing setting. In general, one-of-a-kind production nature and temporary organizational structures of ETO firms may hinder the successful implementation of continuous improvement programmes. This study investigates this issue deeper through a single case study in a producer of offshore oil platforms and outlines the barriers and success factors for continuous improvement in ETO manufacturing.
\end{abstract}

Keywords: Engineer-to-Order, Continuous Improvement, Project-based manufacturing

\section{Introduction}

Complex Engineer-to-Order (ETO) manufacturing is characterized by low volumes, low standardization, high engineering complexity, long lead times, and temporary project-based organizations [1]. This archetype of ETO products are the traditional "oneof-a-kind" products such as construction of ships, oil platforms, and nuclear plants [2]. High-cost countries have long been upholding a competitive advantage in complex ETO businesses with their highly skilled work force and tradition of innovating. Nevertheless, sustaining this competitive advantage is becoming more and more challenging with the increasing ability of low-cost countries to produce complex ETO products in lower costs. It has therefore become of vital importance to improve the cost efficiency of the ETO production operations for high-cost countries.

The application of lean principles to complex ETO settings is therefore receiving a significant attention in recent research studies [3]. One of the central principles of lean phenomena is "continuous improvement" which can be defined as an ongoing and systematic approach to perform improvements on products, services, and processes [4]. These improvements can be incremental or breakthrough. While research shows that most corporate change programmes fail [5], complex ETO characteristics imply even bigger challenges for continuous improvement programmes. One of a kind projects, temporary organizations and project teams, price-oriented tendering and different types of variabilities are some of the challenging characteristics of the complex ETO firms 
[6]. Besides the unique characteristics of the ETO industry, the human and organizational factors that are built in long tradition of ETO/ one-of-a-kind production also play an important role to hinder ETO companies for successful implementation of continuous improvement programs. This paper focuses on investigating these characteristics and factors, by posing the following research question: How do the characteristics of ETO firms influence the successful implementation of continuous improvement efforts? The paper is structured as follows. First, the research methodology is described, which is followed by the description of the case company. The results of the case study are presented in the next two sections: barriers and success factors of continuous improvement. The paper is concluded by the discussion and future research.

\section{Research Methodology}

The literature is scarce and contains mainly too general information about continuous improvement challenges for complex ETO firms. This issue necessitates conducting field-based studies that can extract deeper insights from practice to literature. As such, this study involves a single case study that is conducted to explore the barriers and success factors for continuous improvement in ETO manufacturing. Qualitative case studies enable generating deeper understanding of the phenomenon within its realworld context and generate new knowledge and theory [7]. The case company is selected from an ongoing industrial research project that focuses on developing a company-specific production improvement programme for the company. The qualitative data is mainly collected through semi-structured interviews with the following participants from the company:

1. The leader of method and technology department that is responsible for developing the detailed method for construction, and sequences of activities.

2. The responsible person for developing the main method and discipline methods for construction.

3. The responsible person for strategy, development, and improvement projects within construction.

Interview guide focused on collecting data about the continuous improvement practices and projects. Collected data was analysed by using a coding and categorization scheme that was based on the following four criteria: (i) concepts that was used often, (ii) interesting and important information, (iii) the interviewee stated explicitly that it was important, (iv) the information matches with the literature. Results of the case study is summarized below in the following sections.

\section{Description of the Case Company}

The case company plan and execute demanding EPCI projects. EPCI is an abbreviation for engineering, procurement, construction and installation, and is a common form of contracting agreement within offshore construction. The case company is a contractor of such projects which means they partly do the work through own labour and partly by subcontracting. The company performs several EPCI projects in parallel, where each 
project is in a different phase. When it comes to design, engineering, and procurement the company is dependent on an engineering partner doing most of it, while construction involve a large number of subcontractors, suppliers, staffing companies as well as own yard facilities, leaders and operators. These subcontractors also shift from one project to another. Installation could be part of project agreements or as options contracts. Hence, it is not only the product itself, the oil platform, that is highly complex, the project organization and its value chain is also highly complex. There are three types of continuous improvement projects performed in the company: (i) long-term strategic projects, (ii) medium-term investment projects, (iii) short-term improvement projects. Most of the projects are medium term investment projects that lasts from two months to one year, with different degree of involvement from departments. Continuous improvement projects consist of the following phases: initialize, investigate, design, implement, and execute the improvement. Each department is responsible for its continuous improvement projects. Most improvement suggestions are initiated top down from leaders. Leaders come up with improvement ideas, list them, and prioritize them according to a standard procedure in a meeting.

\section{Barriers for Continuous Improvement in ETO}

Following barriers were identified through the case study.

The project and construction take the attention and capacity: The ongoing project and construction work may take most of the attention and capacity in the project. This is highly understandable as construction is the process where complex customer requirements are converted to an actual product and deals with strict deadlines. This can lead to lack of capacity and focus allocated for improvements even though there is a desire to perform improvements. Many obligatory works need to be done and prioritized over improvements, such as work tasks, documentation, and human resource management. Improvements give premises and savings over long term; however, people are more concerned with their existing tasks. It can be difficult to show the short-term premises of improvements.

Autonomous and temporary project organization with varying competences and interests of people: Different projects involve different project teams, with autonomous structures in decision making. On one hand this approach is needed to make timely and flexible decisions. On the other hand, the project teams have high authority to adjust their way of working in accordance with the project needs, which brings difficulties to transfer best practice from one project to another. In addition to this factor, people have different competences and approaches that influence the success of the project and improvements. This applies to all levels from project leaders down to supervisors. Some individuals are very open for creating best practices, while some are not so good at documenting their experiences and learnings. A common perception is that "this project is different, improvements from other projects do not apply here". As in many project organisations, this issue results in valuable tacit knowledge, while challenges exist for transferring it between projects.

The authority, competence, and culture of management team: There is a lot of authority and power in project manager positions and those who hold such positions are 
used to lead large projects with high degree of self-determination and skills. When operations are not standardized, the project success is then even more dependent on project manager's personal skills. This may cause that some project managers are reluctant to standardization, as considered by some of the other employees.

Complex organizational structure: Matrix organization with projects and discipline departments aims at cross functional communication and flexibility to allocate resources. However, this structure causes slower execution of improvement projects and make communication more complicated. Process ownership is not straightforward. It is not certain who gets involved in an improvement project, and who is responsible for implementing the results in new projects. The outcome is that decisions must be taken higher in the hierarchy than elsewhere needed.

Local focus and lack of knowledge sharing across the organization and value chain: Many works with continuous improvement, however, some do it cross-functional. Likewise, the capability of understanding thorough processes, sequences and holistic thinking is difficult. It is easy to discuss single processes, but any discussion of the whole can meet resistance due to high complexity. An example of lack of knowledge sharing within the case company is that the improvements carried out are to a little extent mediated to project managers and bidding teams in early project planning phases. If not communicated on early stages, the improvement will likely not be implemented in the project.

Collaboration model with supply chain partners: Diverse types of collaboration models with partners can make it difficult to perform improvements. This is also dependent on the type of improvement. For example, in a joint venture model it can be a substantial challenge to change the practices. The partner can decline the use of resources and time if it is a considerable change.

\section{$5 \quad$ Success Factors for Continuous Improvement in ETO}

Based on the discussions with the case study participants, the following success factors were identified.

Thorough clarification of the scope and implementation of the project: Experiences from the earlier successful improvement projects indicate that people get better committed when they know more about the improvement and how it will contribute to their everyday work. It is also suggested to take incremental improvement steps rather than having big ambitions.

Culture for organizational support, involvement, and ownership: All the three interviewees emphasized that people from construction shop floor should be involved in the improvement projects, in a structured and systematic way. A possible approach to realize this factor is to choose a representative from construction, who has the ownership and responsibility of improvement projects at construction. The representative can improve the communication between departments, get feedbacks from parts, contribute to decisions, improve the involvement of shop floor, and bring improvement ideas from construction shop floor to the managerial levels. The shop floor people can see the improvement potentials, working closer to the actual workplace. This approach can also contribute to the engagement of the construction shop floor. 
Prioritizing process improvement before technological improvements: Most enterprises hurry into finding technological solutions for their process-related and managerial problems. Prior to a technological improvement, a process improvement step should be taken in a holistic manner. One of the most challenging issue in complex ETO companies is the complex organizational structure with many disciplines, departments, and groups of people that should cooperate and communicate effectively. There is much to gain in streamlining the processes and value stream in such complex organizational settings before looking at the appropriate technological support.

Training of project managers: The interviewees were agreed on that improvements have a higher chance to succeed with managers that have the engagement for improvement, innovations, and new technologies. Besides the process improvement initiatives, leadership improvement initiatives, such as lessons learned for leaders, should be established. The personal development programs for leaders should include the continuous improvement topic.

Easy and intuitive communication of improvements: In such project-oriented ETO organizations, the project team has the authority to choose if they want to apply the improvement suggestions from other projects, as stated earlier. However, such improvement suggestions are usually written in project reports which is often overseen due to lack of time. This fact necessitates easy and intuitive solutions to communicate the improvement suggestions, such as providing a shortlist of lessons learned. The project leaders should be followed up by going through the shortlist with them and making them to take a deliberate choice to apply or not one by one. As such, the most important improvements can be communicated directly.

Improvement supporting partnership model with the value chain actors: Contract models with customers and partners should encourage improvement projects and leverage them through the whole value chain.

\section{Experiences from Previous Improvement Projects}

This chapter provides experiences from two improvement projects, exemplifying some of the barriers and success factors identified in the previous chapters. The first example can be considered as successfully implemented, while the second one has failed in terms of applying the improvement across the whole organization.

Improvement project one - Developing an operation room for monitoring and control of operations: In one of the large construction projects, the method and technology department has introduced a concept called operation room that aids the monitoring, coordination, and control needs of the project. The leader of the improvement project involved the construction department effectively and provided training about the operation room. There was a long planning process before the improvement project started. The scope and responsibilities were clarified to everyone. There was a reluctance from the people to implement it in the beginning, however people became more and more engaged when they saw that it was aiding their daily work tasks. The communication and feedback practices were facilitated among all levels of management and shop floor. The improvement project has received good feedback from people and were leveraged 
in the following projects. This case mainly exemplifies the importance of involving all relevant parties, clarifying the scope of the improvement, and intuitive communication.

Improvement project two - Improvement of the work instructions: In one of the construction projects, the company found out that the work instructions should be specified more to utilize the worker capacities better. This improvement project has also involved all relevant parties from the company. The project resulted in a good quality of work instructions. However, the instructions could not be implemented in another construction project because the manager of the other project was sceptical about the new instructions. The improved instructions were then used in another large construction project as the manager of that project saw the necessity of the detailed instructions. This case mainly exemplifies the impact of the project manager's authority and culture on implementation of improvements.

\section{$7 \quad$ Conclusion}

This paper discussed the barriers and success factors to perform continuous improvement projects in complex ETO manufacturing, through a single case study. While a single case study poses limitations in terms of the generalisability of these findings, it also provides deeper understanding of the studied phenomena. Hence, the results of this study should be considered to provide preliminary contributions to the limited body of knowledge in continuous improvement in ETO firms, and to the research question posed. Future research should focus on conducting more case studies in relevant complex ETO environments to validate and enrich the findings of the study, with the aim of increasing the success rate of the continuous improvement projects in ETO firms.

\section{References}

1. Semini, M., Haartveit, D. E. G., Alfnes, E., Arica, E., Brett, P. O., and Strandhagen, J. O.: Strategies for customized shipbuilding with different customer order decoupling points. Proceedings of the Institution of Mechanical Engineers, Part M: Journal of Engineering for the Maritime Environment 228(4), 362-372 (2014).

2. Willner, O., Powell, D., Gerschberger, M., and Schönsleben, P.: Exploring the archetypes of engineer-to-order: an empirical analysis. International Journal of Operations \& Production Management 36(3), 242-264 (2016).

3. Powell, D., Strandhagen, J. O., Tommelein, I., Ballard, G., and Rossi, M.: A new set of principles for pursuing the lean ideal in engineer-to-order manufacturers. Procedia CIRP 17, 571-576 (2014).

4. Morgan, J.M., Liker, J.K.: The Toyota product development system. Vol. 13533. Productivity Press, New York (2006)

5. Aiken, C., Keller, S.: The irrational side of change management. McKinsey Quarterly 2(10), 100-109 (2009).

6. Höök, M., Stehn, L.: Applicability of lean principles and practices in industrialized housing production. Construction management and Economics 26(10), 1091-1100 (2008).

7. Eisenhardt, K.M., Graebner, M.E.: Theory building from cases: opportunities and challenges. Academy of Management journal 50(1), 25-32 (2007). 